\title{
ĐÁNH GIÁ KẾT QUẢ PHẪU THUÂ̂T ĐIỀU TRI GÃY KÍN LIÊN MẤU CHUYỂN XƯƠNG ĐÙI TẠI BỆNH VIỆN VIỆT ĐỨC
}

\section{TÓM TẮT}

Chúng tôi tiến hành nghiên cứu hồi cứu trên 71 bênh nhẩn gãy liên mấu chuyển xương đùi, được điều trị phẫu thuật tại Bệnh viện Việt Đức từ tháng 8 đến 10/2020. Tuổi trung bình 71 tuổi, trong đó tuổi trên 83 tuổi chiếm hơn 40\%. Muc tiêu: Đánh giá kết quả phẫu thuật điều trị gãy kín liên mấu chuyển xương đùi tại Bệnh viện Việt Đức. Phương pháp nghiên cứu: Lựa chọn bệnh nhân theo tiêu chuẩn lựa chọn, lấy hồ sơ bệnh án, thu thập thông tin theo bệnh án nghiên cứu, đánh giá kết quả lâm sàng và Xquang sau mổ sau 6 tháng. Kết quả: Sau mô trung bình 7 tháng, kết quả lâm sàng tốt và rất tốt đạt $83 \%$ đối với nhóm kết hợp xương và $75 \%$ đối với nhóm thay khớp háng bán phần. Độ áp khít $>80 \%$ sau thay khớp chiếm $96,5 \%$; tỷ lệ liền xương tốt và rất tốt chiếm $64,3 \%$, liền xương mức trung bình là 35,7\% ở nhóm kết hợp xương. Kết luân: Với thời gian theo dõi trung bình 7 tháng đối với nhóm phẫu thuật kết hợp xương và thay khớp háng bán phần điều trị gãy liên mâu chuyển xương đùi, kết quả khả quan, đặc biệt tỷ lệ liền xương xương khá cao ở nhóm kết hợp xương.

\section{SUMMARY \\ RESULT OF SURGERY TREATMENT FOR INTERTROCHANTERIC FRACTURE IN VIET DUC HOSPITAL}

The operative treament for intertrochanteric fracture was conducted in 71 patients, mean age $71,68 \pm 16,78$, male to female ratio is $1 / 2,23$, in which 42 patients with internal fixation and 29 patients with hemiarthroplasty. In internal fixation group, $97,96 \%$ patients achieved good reduction, with no complication and $83,3 \%$ patients had good to very good functional result. In hemiarthroplasty group, $100 \%$ stems were in neutral position, $96,55 \%$ patients had stem-canal ratio $\geq 80 \%$, intraoperative femoral fracture occurred in $6,9 \%$ patients, post-operative complication rate is $6,9 \%$ and $75,9 \%$ patients had good to very good functional result. There is no difference in functional outcome between internal fixation group and hemiarthroplasty group.

Key words: intertrochanteric fracture, internal fixation, hemiarthroplasty, operative treatment.

\section{I. ĐĂT VẤN ĐỀ}

Gãy liên mấu chuyển xương đùi là gãy xương thường gặp ở người cao tuổi, trên nền loãng

\section{${ }^{1}$ Dai Hoc Y Hà Nôi}

Chịu trách nhiệm chính: Ứng Trần Trí

Email: ungtrantri@gmail.com

Ngày nhận bài: 7.4.2021

Ngày phản biện khoa học: 25.5.2021

Ngày duyệt bài: 7.6.2021

\section{Úng Trần Trí1, Dương Đình Toàn ${ }^{1}$}

xương và thường do cơ chế ngã ngồi. Dù tỉ lệ liền xương cao do gãy ở nơi có nhiều cớ, tưới máu tốt nhưng tử vong còn cao ngay cả ở nhóm được điều trị phẫu thuật lên đến 4,5\%, chủ yếu ở nhóm cao tuổi và mắc các bệnh mạn tính. Điều trị gãy liên mấu chuyển xương đùi hiện nay chủ yếu là phẫu thuật, các phương pháp đa dang như mổ kết hợp xương bên trong với nẹp DHS, nepp vít khóa, đinh nội tủy hoặc mổ thay khớp háng bán phần. Hàng năm, Bệnh viện Hữu nghị Việt Đức tiếp nhận và điêuu trị phẫu thuật cho hàng trăm bệnh nhân gãy liên mấu chuyển xương đùi bằng nhiều phương pháp khác nhau, nghiên cứu này nhằm đánh giá kết quả phẫu thuật điều trị gãy liên mấu chuyển xương đùi tại Bệnh viện Hữu nghị Việt Đức.

\section{II. ĐỐI TƯợNG VÀ PHƯƠNG PHÁP NGHIÊN CỨU}

2.1. Thời gian nghiên cứu: $01 / 08 / 2020$ $31 / 10 / 2020$

2.2. Địa điểm nghiên cứu: Viên chấn thương chỉnh hình Bệnh viện Hữu Nghị Việt Đức

2.3. Đối tượng nghiên cứu: Bệnh nhân được chẩn đoán gãy liên mấu chuyển xương đùi do chấn thương được điều trị phẫu thuật kết hợp xương hoặc thay khớp bán phần tại Viện Chấn thương chỉnh hình Bệnh viện Việt Đức. Bênh nhân có hồ sơ bệnh án đầy đủ thông tin và đồng ý tham gia nghiên cứu.

Tiêu chuẩn loại trừ: Gãy xương do các nguyên nhân không phải chấn thương hoặc có các bệnh lý gây cản trở vận động, đi lại từ trước. Bệnh nhân không đồng ý tham gia nghiên cứu.

2.4. Thiết kế nghiên cứu: Nghiên cứu mô tả cắt ngang, hồi cứu.

2.5. Mẫu nghiên cứu: Chọn mẫu thuận tiện. Các bệnh nhân đủ tiêu chuẩn được lựa chọn theo một mẫu bệnh án thống nhất

2.6. Quản lý, phân tích số liệu: Nhập và phân tích số liệu bằng phần mềm SPSS 20.0. Các kết quả được tính toán: tỷ lệ phần trăm, so sánh các tỷ lệ, mối tương quan giữa các biến số. Các test nghiên cứu: $x^{2}$ test, $T$ test với $p<0,05$ là sự khác biệt có ý nghĩa thống kê.

\section{KẾT QUẢ NGHIÊN CỨU}

\section{1. Đặc điểm đối tượng nghiên cứu}

Nghiên cứu trên 71 bệnh nhân gãy liên mấu chuyển xương đùi được điều trị phẫu thuật tại Bệnh viện Hữu Nghị Việt Đức chúng tôi thu được 
kết quả như sau:

Đặc điểm của nhóm đối tượng nghiên cứu được thể hiện trong bảng 1 . Trong nghiên cứu, đa số là bệnh nhân là nữ giới, cao tuổi, 78,9\% bệnh nhân trên 60 tuổi, bệnh nhân già nhất là 101 tuổi. Cơ chế tại nạn thường gặp là ngã ngồi, với phân loại ổ gãy trước mổ là A2 chiếm ưu thế.

Có 4 phương pháp phẫu thuật được sử dụng bao gồm: 40 bệnh nhân mổ kết hợp xương bằng nẹp khóa chiếm $56,4 \%$; 29 bệnh nhân mổ thay khớp háng bán phần chiếm 40,8\%; 1 bệnh nhân mổ kết hợp xương bằng nẹp vít thường chiếm $1,4 \%$ và 1 bệnh nhân mổ kết hợp xương bằng đinh nội tủy chiếm 1,4\%.

Về các yếu tố liên quan đến điều trị phẫu thuật: thời gian phẫu thuật trung bình là 57,51 phút; thời gian phẫu thuật thay khớp háng bán phần trung bình là 55,17 phút ngắn hơn có ý nghĩa thống kê so với thời gian phẫu thuật kết hợp xương trung bình là 59,12 phút. Tỉ lệ phải truyền máu trong mổ là $39,44 \%$, tỉ lệ này ở nhóm mổ kết hợp xương là $35,71 \%$ và ở nhóm mổ thay khớp háng bán phần là $44,83 \%$. Thời gian nằm viện trung bình là 9,06 ngày, ở nhóm mổ kết hợp xương là 8,67 ngày và ở nhóm mổ thay khớp là 9,62 ngày.

\section{Bảng 1: Đặc điểm bệnh nhân nghiên cứu theo nhóm phẫu thuật}

\begin{tabular}{|c|c|c|c|}
\hline Đặc điểm & $\begin{array}{c}\text { Kết hợp xương } \\
\mathbf{( n = 4 2 )}\end{array}$ & $\begin{array}{c}\text { Thay khớp bán } \\
\text { phấn } \mathbf{( n = 2 9 )}\end{array}$ & $\begin{array}{c}\text { Tổng } \\
\mathbf{( n = 7 1 )}\end{array}$ \\
\hline Tuôi trung bình & $63,19 \pm 16,63$ & $83,97 \pm 5,85$ & $71,68 \pm 16,78$ \\
\hline Tỉ lệ nam : nữ & $1: 1,33$ & $1: 6,25$ & $1: 2,23$ \\
\hline Tî̀ lệ mắc bệnh mạn tính & $21,4 \%$ & $31,0 \%$ & $25,35 \%$ \\
\hline Cơ chế tai nạn: Ngã ngồi & $52,4 \%$ & $93,1 \%$ & $69,01 \%$ \\
Tai nạn giao thông & $35,7 \%$ & $0 \%$ & $21,13 \%$ \\
Khác & $11,9 \%$ & $6,9 \%$ & $9,86 \%$ \\
\hline Phân loại ố gãy theo AO: A1 & $19,0 \%$ & $10,3 \%$ & $15,5 \%$ \\
A2 & $57,1 \%$ & $89,7 \%$ & $70,4 \%$ \\
A3 & $23,8 \%$ & $0 \%$ & $14,4 \%$ \\
\hline
\end{tabular}

Chúng tôi ghi nhận 02 bệnh nhân gặp biến chứng gãy thân xương đùi trong phẫu thuật thay khớp háng bán phần chiếm tỉ lệ $6,9 \%$. Sau mổ có 2 bệnh nhân gặp biến chứng chiếm tî lệ 2,8\%, 01 bệnh nhân bị viêm phổi sau mổ và 01 bệnh nhân bị huyết khối tĩnh mạch sâu chi dưới. Cả 2 bệnh nhân này đều ở nhóm mổ thay khớp háng bán phần.

\subsection{Kết quả nghiên cứu}

Đánh giá kết quả nắn chỉnh ổ gãy ở nhóm mổ kết hợp xương cho thấy $97,96 \%$ bệnh nhân được nắn chỉnh về giải phẫu, phục hồi góc cổ thân về khoảng sinh lý, chỉ có 01 bệnh nhân chiếm 2,04\% trên phim Xquang sau mổ góc cổ thân chỉ đạt 98 độ, còn di lệch gập góc trước sau trên phim nghiêng đo được là 16 độ.

Bảng 2: Mức độ áp khít của chuôi khớp $(n=29)$

\begin{tabular}{|c|c|c|}
\hline Mức độ áp khít & Số lượng & Tỉ lệ \% \\
\hline$\geq 80 \%$ & 28 & 96,55 \\
\hline$<80 \%$ & 1 & 3,45 \\
\hline
\end{tabular}

Kết quả Xquang sau mố ở nhóm bệnh nhân mố thay khớp háng bán phần thây $100 \%$ bệnh nhân có trục trung gian, tức là trục của chuôi khớp tạo với trục ống tủy xương đùi góc nhỏ hơn 5 độ, 96,55\% bệnh nhân có độ áp khít của chuôi khớp đo tại bờ trên mấu chuyển bé $\geq 80 \%$, chỉ có 01 bệnh nhân chiếm 3,45\% có độ áp khít <80\%.

Đánh giá liền xương ở các bệnh nhân mổ kết hợp xương bên trong theo thang điểm RUSH (Radiographic Union Score for Hip) ${ }^{1}$ sau 6 tháng. Kết quả thu được trên 28/42 bệnh nhân mổ kết hợp xương, điểm RUSH trung bình sau 6 tháng là 23,07 , với 3 bệnh nhân ở mức rất tốt chiếm 10,7\%; 15 bệnh nhân ở mức tốt chiếm 53,6\%; 10 bệnh nhân ở mức trung bình chiếm $35,7 \%$ và không có bệnh nhân nào ở mức kém.

Bảng 3: Điểm RUSH sau 6 tháng ở nhóm mổ kết hợp xướng ( $n=28)$

\begin{tabular}{|c|c|c|}
\hline Điếm RUSH & Số lượng & Tỉ lệ \% \\
\hline Rất tô̂t & 3 & 10,7 \\
\hline Tốt & 15 & 53,6 \\
\hline Trung bình & 10 & 35,7 \\
\hline Kém & 0 & 0 \\
\hline Tống & $\mathbf{2 8}$ & $\mathbf{1 0 0}$ \\
\hline
\end{tabular}

Tất cả các bệnh nhân được đánh giá chức năng khớp háng sau mổ theo thang điểm Haris sửa đổi ${ }^{2}$, thời điểm đánh giá chức năng sau mổ trung bình là 7,15 tháng, ngắn nhất là 6 tháng và dài nhất là 8 tháng. Kết quả đánh giá thể hiện ở bảng 4.

Bảng 4: Kêt quả chức năng khớp háng sau mố theo thang điểm Haris sửa đổi

\begin{tabular}{|c|c|c|c|c|}
\hline $\begin{array}{c}\text { Chức } \\
\text { năng } \\
\text { khớp } \\
\text { háng sau } \\
\text { mổ }\end{array}$ & \multicolumn{2}{|c|}{$\begin{array}{c}\text { Kết hợp } \\
\text { xương }\end{array}$} & \multicolumn{2}{|c|}{$\begin{array}{c}\text { Thay khớp } \\
\text { bán phần }\end{array}$} \\
\cline { 2 - 5 } & $\begin{array}{c}\text { Số } \\
\text { lượng }\end{array}$ & $\begin{array}{c}\text { Tỉ lệ̂ } \\
\%\end{array}$ & $\begin{array}{c}\text { Số } \\
\text { Iượng }\end{array}$ & $\begin{array}{c}\text { Tìn } \\
\text { lệ } \\
\%\end{array}$ \\
\hline
\end{tabular}




\begin{tabular}{|c|c|c|c|c|}
\hline Rất tốt & 9 & 21,4 & 4 & 13,8 \\
\hline Tốt & 26 & 61,9 & 18 & 62,1 \\
\hline Trung bình & 5 & 11,9 & 5 & 17,2 \\
\hline Kém & 2 & 4,8 & 2 & 6,9 \\
\hline Tống & $\mathbf{4 2}$ & $\mathbf{1 0 0}$ & $\mathbf{2 9}$ & $\mathbf{1 0 0}$ \\
\hline
\end{tabular}

Kết quả chung tỉ lệ bệnh nhân có chức năng khớp háng sau mổ ở mức tốt và rất tốt là $80,3 \%$. Tî lệ đạt kết quả tốt và rất tốt ở nhóm mổ kết hợp xương là 83,3\% khác biêt không có ý nghĩa thống kê so với nhóm mổ thay khớp háng bán phần là 75,9\%.

\section{BÀN LUÂN}

Kết quả nắn chỉnh ổ gãy ở nhóm mổ kết hợp xương cho thấy đa số các bệnh nhân đều được nắn chỉnh về giải phẫu, phục hồi góc cổ thẩn sinh lý. Chỉ có 01 trường hợp thất bại do sử dụng nẹp vít thường, đây là loại phương tiện kêtt hợp xương không được khuyến cáo đối với gãy liên mấu chuyển xương đùi do không có khả năng cố địnhvững ổ gãy, dể gặp các biến chứng bong, gãy nẹp vít.

Tỉ lệ biến chứng sau mổ là 2,82\%, tính riêng cho nhóm mổ thay khớp háng bán phân là $6,9 \%$ thấp hơn so với các tác giả khác trong nước như Nguyễn Văn Thoan và cộng sự là 13,5\%, Nguyễn Mạnh Linh và cộng sự là 16,2\% $\%^{3,4}$.

Trong nghiên cứu này chúng tôi ghi nhận 02 trường hợp gãy xương đùi trong phẫu thuật thay khớp háng chiếm tỉ lệ 6,9\%. Tác giả M P. Abdel khi thống kê trên 32644 bệnh nhân phẫu thuật thay khớp háng trong vòng 40 năm chỉ ra tỉ lệ gãy thân xương đùi trong phẫu thuật thay khớp háng là $1,7 \%$, nguy cơ tăng gấp 14 lần ở nhóm dùng chuôi không xi măng so với có xi măng, bệnh nhân nữ và trên 65 tuổi cũng có nguy cơ cao bị gãy xương đùi trong phẫu thuật. ${ }^{5}$

Tỉ lệ bênh nhân đạt kết quả tốt và rất tốt ở nhóm mổ kết hợp xương là $83,3 \%$. Kết quả này tương đương với một số tác giả khác cùng nghiên cứu ở Bệnh viện Việt Đức như Nguyễn Hữu Nam và cộng sự năm 2012 nghiên cứu trên 143 bệnh nhân gãy liên mấu chuyển xương đùi điều trị bằng nẹp DHS thấy kết quả tốt và rất tốt là $80,7 \%{ }^{6}$. Tác giả Nguyễn Huy Thành và cộng sự năm 2018 khi nghiên cứu trên 55 bệnh nhân mổ kết hợp xương nẹp khóa điều trị gãy liên mấu chuyển xương đùi thấy tỉ lệ bệnh nhân đạt kết quả tốt và rất tốt là $81,8 \%{ }^{7}$.

Trong nhóm 29 bệnh nhân mổ thay khớp háng bán phần, tỉ lệ bệnh nhân ở mức tốt và rất tốt là $75,9 \%$. Kết quả này tương tự nhiều tác giả như Nguyễn Văn Thoan và cộng sự khi nghiên cứu trên 35 bệnh nhân mổ thay khớp háng bán phần chuôi dài không xi măng thấy tỉ lệ bệnh nhân đạt kết quả tốt và rất tốt là $82,8 \%{ }^{3}$. Tác giả Nguyễn Mạnh Linh và cộng sự khi nghiên cứu trên 37 bệnh nhân mổ thay khớp háng bán phần điều trị gãy liên mấu chuyển xương đùi thấy kết quả tốt và rất tốt là $71,9 \%{ }^{4}$.

Tỉ lệ bệnh nhân đạt kết quả tốt và rất tốt ở cả 2 nhóm phẫu thuật khác biệt nhau không có ý nghĩa thống kê với $p>0,05$. Các nghiên cứu so sánh thay khớp háng bán phần và kết hợp xương trong điều trị gãy liên mấu chuyển xương đùi đều chỉ ra phẫu thuật thay khớp háng cho kết quả tương đương hoặc tốt hơn về mặt chức năng như tác giả K. Sinno năm 2010 chỉ ra phẫu thuật thay khớp bán phần cho kết quả tốt hơn, giảm biến chứng sau mổ và rút ngắn thời gian hạn chế chịu lực ${ }^{8}$. Tác giả Dong-peng $T u$ và cộng sự năm 2020 cũng chỉ ra phẫu thuật thay khớp háng bán phần điều trị gãy liên mấu chuyển xương đùi có tỉ lệ biến chứng thấp hơn, thời gian tì chịu lực sớm hơn so với phẫu thuật kết hợp xương bên trong9 .

\section{KẾT LUẬN}

Phẫu thuật điều trị gãy liên mấu chuyển xương đùi ở Bệnh viện Hữu Nghị Việt Đức cho kết quả tốt. Ở nhóm mổ kết hợp xương, tỉ lệ nắn chỉnh ổ gãy đạt giải phẫu là $97,96 \%$, không có bệnh nhân nào có biến chứng trong và sau mổ, tỉ lệ bệnh nhân đạt kết quả tốt và rất tốt là $83,3 \%$, tỷ lệ liền xương sau 6 tháng ở mức tốt và rất tốt chiếm $64,3 \%$, liền xương mức trung bình là $35,7 \%$. Ở nhóm bệnh nhân mổ thay khớp háng bán phần, 100\% chuôi khớp ở vị trí trung gian, 96,55\% bệnh nhân có độ áp khít $\geq$ $80 \%$, tî lệ biến chứng trong mổ và sau mổ đều là $6,9 \%$, tỉ lệ bệnh nhân đạt kết quả tốt và rất tốt là 75,9\%. Phẫu thuật kết hợp xương bên trong và thay khớp háng bán phần trong điều trị gãy liên mấu chuyển xương đùi cho kết quả tương đương nhau.

\section{TÀI LIÊU THAM KHẢO}

1. Bhandari $\mathbf{M}$, Chiavaras $\mathbf{M} M$, Parasu $\mathbf{N}$, et al. Radiographic union score for hip substantially improves agreement between surgeons and radiologists. BMC Musculoskelet Disord. 2013;14:70. doi:10.1186/1471-2474-14-70

2. Mahomed NN, Arndt DC, McGrory BJ, Harris WH. The Harris hip score: comparison of patient self-report with surgeon assessment. J Arthroplasty. 2001;16(5):575-580. doi:10.1054/ arth.2001.23716

3. Nguyến Văn Thoan. Đánh giá kết quả thay khớp háng bán phần chuôi dài không xi măng trong điều trị gãy liên mấu chuyển xương đùi tại bệnh viện Việt Đức. Luận Văn Thạc Sỹ Học. 2018;Đại học Y HN̂̉. 
4. Nguyễn Mạnh Linh. Đánh giá kết quả phẫu thuât thay khớp háng bán phần không xi măng điều trị gãy liên mấu chuyên xương đùi ở bệnh nhân trến 80 tuổi. Luận Văn Thạc Sỹ Học. 2020;Đai hoc Y Hà Nôi.

5. Abdel MP, Watts CD, Houdek MT, Lewallen DG, Berry DJ. Epidemiology of periprosthetic fracture of the femur in 32644 primary total hip arthroplasties: a 40-year experience. Bone Jt J. 2016;98-B(4):461-467. 620X.98B4.37201

6. Ngô Văn Toàn, Trân Trung Dũng, Nguyễn Hữu Nam. Điều trị gãy liên mấu chuyển xương đùi bằng nẹp DHS tại bệnh viện Việt Đức. Tạp Chí Nghiên Cứu Học. 2013;84 (4):69-75.
7. Nguyễn Huy Thành. Đánh giá kết quả điều trị gãy liên mấu chuyển xương đùi bằng kết hợp xương nẹp khóa tại Bệnh viện Hữu nghị Việt Đức. Đại Học Hà Nội. 2018; Luận văn thạc sĩ Y học.

8. Sinno $K$, Sakr $\mathbf{M}$, Girard J, Khatib H. The effectiveness of primary bipolar arthroplasty in treatment of unstable intertrochanteric fractures in elderly patients. North Am J Med Sci. 2010;2(12):561-568. doi:10.4297/najms.2010.2561

9. Tu D, Liu $\mathbf{Z}$, Yu $\mathbf{Y}$. Internal Fixation versus Hemiarthroplasty in the Treatment of Unstable Intertrochanteric Fractures in the Elderly: A Systematic Review and Meta-Analysis. Orthop Surg. 2020;12(4):1053-1064. doi:10.1111/os.12736

\section{HÌNH THÁI ỐNG TỦY RĂNG SỐ 7 HÀM DƯớI TRÊN PHIM CBCT}

\section{Đỗ Thị Thu Hương*, Đinh Diệu Hồng*, Phạm Thị Thu Hiền*, Nguyễn Anh Chi*, Phạm Như Hải*}

\section{TÓM TẮT}

Chụp cắt lớp vi tính chùm tia hình nón (CBCT) là phương pháp hố trợ đắc lực cho điều trị nội nha. Mục đích của nghiên cứu này là xác định hình thái của ống tủy răng hàm 7 hàm dưới. CBCT của 346 bệnh nhân đã được sử dụng. Kết quả như sau: Số lượng chân răng theo thứ tự: 3 chân răng $(1,7 \%), 2$ chân răng $(97,8 \%), 1$ chân răng $(0,5 \%)$. Sự khác nhau bên phải và trái không có ý nghĩa thống kê. $47,7 \%$ răng chân gân chỉ có 1 ống tủy, nữ $(56,4 \%)$ cao hơn nam $(36,1 \%) .96,4 \%$ răng chân xa có 1 ống tủy. Hình thái ống tủy chữ $\mathrm{C}$ chiếm $21,7 \%$, trong đó hinh thái $\mathrm{C} 1$ chiếm $14,2 \%$ và $C 2$ chiếm $5,5 \%$. Sự khác nhau bên phải và trái không có ý nghĩa thống kê, nhưng hay gặp ở nữ $(24,9 \%)$ hơn là ở nam $(17,5 \%)$.

Tư khóa: ống tủy, nội nha, cone-beam, răng 7 hàm dưới.

\section{SUMMARY \\ ROOT CANAL MORPHOLOGY OF} MANDIBULAR SECOND MOLARS ON CBCT

Cone-beam computed tomographic (CBCT) imaging is a useful method for endodontic therapy. The aim of this study was to identify morphology of second lower molar root canal . CBCT of 346 patients were used. Results were as follows: Number of roots is $3(1,7 \%), 2(97,8 \%), 1(0,5 \%)$. No difference on the right and left side. $47,7 \%$ of the mesio-bucal root teeth have only 1 root canal, women $(56,4 \%)$ higher than men $(36,1 \%)$, the difference . $96,4 \%$ distal roots have only one canal. The morphology of the C-shaped canal accounts for $21,7 \%$, of which the $\mathrm{C} 1$ form accounts for $14,2 \%$ and C2 accounts for $5,5 \%$. No

*Trường Đại học Y Dược-Đại học Quốc Gia Hà Nội Chịu trách nhiệm chính: Đinh Diệu Hồng Email: dieuhong201@gmail.com

Ngày nhận bài: 8.4.2021

Ngày phản biên khoa học: 25.5 .2021

Ngày duyệt bài: 9.6.2021 difference between right and left, but more common in women $(24,9 \%)$ than in men $(17,5 \%)$.

Key words: root canal, endodontic, cone-beam computed tomographic,

\section{I. ĐẶT VẤN ĐỀ}

Hình thái học tủy răng là một vấn đề rất phức tạp liên quan chặt chẽ đến chuyên ngành điều trị nội nha, đặc biệt là với nhóm răng hàm lớn việc điều trị tủy răng gặp nhiêu khó khăn hơn nhóm răng trước. Việc nhận biết được các biến thể trong hình thái ống tưy rất quan trọng để điêu trị nội nha thành công, cho phép bác sĩ tiên lượng điều trị tránh thất bại, đặc biệt trong quá trình sưa soạn và hàn kín ống tủy. Do mổi răng đều có đặc điểm riêng, do đó mỗi nhóm răng sẽ có một số lượng lớn các biến thể về số lượng và hình thái ống tủy. Những đặc điểm như vậy làm khó khăn trong việc tạo hình, làm sạch và trám bít hệ thống ống tủy ba theo 3 chiêu không gian.

Rắng hàm lớn hàm dưới thứ hai thường được mô tả trong tài liệu là có 2 chân răng và 3 ông tủy mà chưa nêu ra được các biến thể cũng như tỷ lệ các biến thể đó để giúp các bác sĩ lâm sàng lựa chọn công cụ và phương pháp sửa soạn và hàn kín hệ thống ống tủy một cách phù hợp.

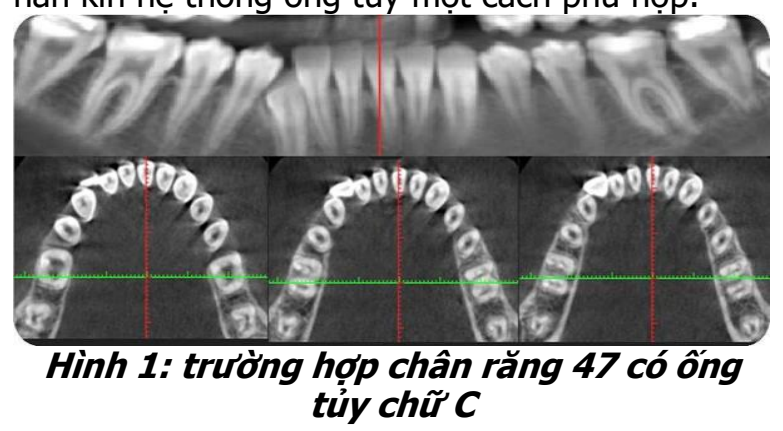

